\title{
Abnormal uterine bleeding: role of sonography and histopathology in endometrial study with emphasis on the organic causes
}

\author{
M. Supriya ${ }^{1, *}$, Atiya Begum² \\ ${ }^{\mathbf{1}}$ Assistant Professor, ${ }^{2}$ Professor, Dept. of Pathology, Deccan College of Medical Science, Hyderabad, Telangana, India \\ *Corresponding Author: \\ Email: supriyamed.sunki@gmail.com
}

Received: $04^{\text {th }}$ September, 2017

Accepted: $16^{\text {th }}$ October, 2018

\begin{abstract}
Introduction: Abnormal uterine bleeding (AUB) is the most common complaint in women of all age groups. The causes for abnormal bleeding needs to be evaluated before subjecting the patient to complicated surgical procedures. Transvaginal sonography is a simpleoutpatient procedure to identify suitable candidates for endometrial biopsy which provides an accurate diagnosis.

Aims and Objectives: 1. To emphasize on the correlation of sonology and histopathological findings and to provide the cause of pathology for Abnormal Uterine Bleeding (AUB) in majority of cases.

2. To study the clinical data of the patients presenting with AUB and its histopathological spectrum.

Materials and Methods: This was a prospective study conducted in the Department of Pathology over a period of one year from January 2016 to December 2016. Endometrial biopsies of patients of all age groups presenting with a chief complaint of Abnormal uterine bleeding and abnormal USG findings were included in the study while inadequate biopsies and patients with genital infections, pregnanacy-complications were excluded. The biopsies were processed as per the standard protocol. Histopathological examination was done and the diagnosis was given. Results were statistically analyzed.

Results: A total of 87 cases were analyzed based on age, clinical presentation, parity, correlation of sonographyhistopathological findings was done and the results were found to have statistically significant $\mathrm{p}$ values.

Conclusion: A combination of sonography with histopathology provides an accurate diagnosis for AUB in most of the cases, specifically those with organic pathology.
\end{abstract}

Keywords: Abnormal uterine bleeding, histopathology, organic pathology, transvaginal sonography.

\section{Introduction}

Endometrium being a dynamic tissue undergoes cyclical changes comprising of proliferation, maturation, shedding during the menstrual cycle. The menstrual cycle is regulated by sex steroid hormones produced from the ovary, which in-turn is under the effect of the hormones produced by pituitary and hypothalamus. So a disturbance in the pituitary hypothalamus - ovarian axis which governs menstruation, it results in abnormal uterine bleeding. ${ }^{1}$

Abnormal uterine bleeding (AUB) is a debilitating condition and a most common complaint with $33 \%$ of gynaecological referrals. ${ }^{2}$ It affects $14-25 \%$ of women in the reproductive age ${ }^{3}$ and in perimenopausal and postmenopausal women it accounts for $69 \%$ of referrals. ${ }^{4}$ Abnormal bleeding is of major concern in perimenopausal and postmenopausal women as endometrial cancers are more common in this age group, accounting for about $10 \%$ of cases. ${ }^{5}$ AUB has varied clinical presentations but most commonly it presents as menorrhagia, polymenorrhea, polymenorrhagia, metrrrhagia, and menometrorrhagia. ${ }^{6}$ FIGO (Federation of International of Gynecologists and Obstetricians) adopted a new classification system which accommodates both the structural/organic causes (PALM - Polyp, Adenomyosis, Leiomyoma, Malignancy and hyperplasia) and non- structural/functional causes (COEIN - Coagulopathy, Ovulatory disorders, Endometrial, Iatrogenic and Not otherwise classified). This classification helps to provide the accurate diagnosis and treatment options. ${ }^{3}$

Histopathological study of Endometrium in different age groups for AUB helps in identifying the pathology and to triage the patients for treatment based on medical options, thereby decreasing the need for complications associated with surgeries and enhancing the quality of life. $^{7}$ Transvaginal/transabdominal ultrasonography is another diagnostic test which helps to study the endometrium. ${ }^{8}$ Each of these diagnostic techniques has their flaws and merits. Dilatation and Curettage $(\mathrm{D} \& \mathrm{C})$ is a blind procedure and with only a small part being sampled, it is likely to miss focal lesions such as polyps and fibroids, ${ }^{9}$ whilst ultrasound is unable to differentiate between endometrial hyperplasia, endometrial polyps and early cancers. Though histopathological interpretation provides an accurate diagnosis, it is not imperative to subject all the patients to D\&C especially in the younger age group where non-functional causes predominate. Ultrasonography can be used as a screening tool to select the patients for endometrial biopsy in investigating a case of AUB and as sonography being a non-invasive procedure it has good patient's compliance. ${ }^{9}$ Hence, with the combination of two 
diagnostic modalities there are less chances to miss a pathology.

Specific objective of the present study was to determine the histopathological spectrum of endometrium in AUB in different age groups and also to correlate clinic-sonological findings with histopathological results for the organic causes of endometrial pathology

\section{Materials and Methods}

This was a prospective study conducted in the Department of Pathology in a tertiary care hospital over a period of one year from January 2016 to December 2016. All the endometrial biopsy specimen along with requisition form containing the patient personal, clinical and sonological (transvaginal) details were received in the pathology lab. Only those cases with a clinical complaint of abnormal bleeding were included in the study. All the specimens were received in 10\% formalin. They were studied grossly and the entire tissue was submitted for processing. Four to six-micron thick paraffin embedded sections were taken and stained by haematoxylin and eosin. The slides were examined under the light microscope by the pathologist and the diagnosis was made.

\section{Inclusion Criteria:}

1. All the patients presenting with a chief complaint of abnormal uterine bleeding and abnormal USG findings.

\section{Exclusion Criteria:}

1. Hysterectomy specimen

2. Patients with genital tract infections

3. Inadequate biopsies

4. Pregnancy related complications

Statistical Analysis: The data was entered in Microsoft excel and analysis was done using SPSS version 20.

Descriptive analysis of the data was done. The results on categorical measurements are presented as percentages and the significance is assessed at $5 \%$ level of significance. Chi square test was used to find out the significance of study parameters on a categorical scale between two groups.

\section{Results}

A total of 106 endometrial biopsy specimens were received in the department of Pathology. Of which 96 cases $(91.42 \%)$ presented with a clinical complaint of abnormal bleeding and the remaining 9cases $(8.57 \%)$ infertility was the main complaint. Of the 96 cases, nine cases were excluded as in 3 cases the biopsy material was inadequate and the remaining 6 cases were diagnosed as retained products of conception. Hence, a total of 87 cases are evaluated in the present study.
The age of the patients were in the range of 20-56 years. Out of the 87 patients presenting with abnormal uterine bleeding, maximum were in the age group of 40-49 years $(40.22 \%)$ and minimum cases with $11.49 \%$ were in the age group 20-29 years. AUB has varied clinical presentation. The predominant pattern was menorrhagia found in 59.7\% (52cases) followed by an equal incidence of metrorrhagia and continuous PV bleeding in $9.19 \%$ (8 cases). Most of the women were multiparous $(\geq 2)$ accounting for $79.3 \%$ (69 cases).

The most common sonographic finding (Table 1) in the patients with abnormal uterine bleeding was thickened endometrium, found in $55.17 \%$ (48 cases).

In the present study majority of the cases $(80.75 \%)$ had organic pathology. Proliferative endometrium (58.82\%) was found to be predominant among the functional cause. In Proliferative endometrium the glands are uniform, round and lined by pseudostratified columnar cells and no evidence of secretions with intervening compact stroma composed of spindle-cells. Hyperplasia was the most common organic pathology of AUB in $71.42 \%$ of cases. Simple hyperplasia was the most common type (Table 2) of hyperplasia present in $88 \%$ of cases

The maximum number of patients were in the age group of 40-49 years (40.22\%) with hyperplasia as the most common pathology in $24.1 \%$ (21 cases), followed by polyps in $10.3 \%$ ( 9 cases); (Table 3 ). These findings were found to be statistically significant ( $p$ value= 0.014). In cases diagnosed as hyperplasia the the hisological findings showed increase in gland to stromal ratio. Cases diagnosed as simple and complex hyperplasia had architectural difference where the increased number of glands are either round and regular or cystically dilated in simple hyperplasia (Fig. 1) and the glands presented with back-to-back arrangement (Fig. 2), branching and irregular angulation in complex hyperplasia. Atypical hyperplasias showed the presence of cytologic atypia comprising of loss of polarity with enlarged, hyperchromatic nuclei and prominent nucleoli. (Fig. 2) Cases with polyp as the diagnosis had hisological findings of endometrial fragments lined by surface epithelium (Fig. 3) with glands of varying sizes and few cystically dilated (Fig. 4). The stroma was fibrotic with presence of thick-walled blood vessels.

Sonological findings correlated with histopathological diagnosis for organic pathology (Table 4) in 70cases (hyperplasis \& polyps). The sensitivity of sonography in detecting the organic causes of AUB is $80.4 \%$. These findings were statistically significant $(\mathrm{p}$ value $=0.000)$.

In the present study (Table 5) the cases with endometrial thickness (ET) of $\geq 7 \mathrm{~mm}$ were diagnosed on histopathological examination to have organic pathology. The sensitivity to detect the presence of hyperplasia is $57.8 \%$ and organic cause is $73.6 \%$ with an ET of $7-15 \mathrm{~mm}$ and ET of $>15 \mathrm{~mm}$ has $100 \%$ sensitivity to detect the organic causes of AUB. This 
correlation was statistically proven to be significant ( $\mathrm{p}$

value $=0.000)$.

Table 1: Ultrasonography (USG) findings of patients presenting with AUB

\begin{tabular}{|l|c|c|}
\hline USG findings & Number $(\mathbf{N})$ & Percentage $(\boldsymbol{\%})$ \\
\hline Bulky uterus & 23 & 26.43 \\
\hline Thickened Endometrium & 48 & 55.17 \\
\hline Polyp & 16 & 18.39 \\
\hline Total & 87 & 100 \\
\hline
\end{tabular}

Table 2: Distribution of cases based on histopathological diagnosis of endometrial biopsies

\begin{tabular}{|c|c|c|}
\hline \multicolumn{3}{|l|}{ Functional causes } \\
\hline Histopathological diagnosis & Number $(\mathbf{N})$ & Percentage (\%) \\
\hline Proliferative endometrium & 10 & 58.82 \\
\hline Secretory endometrium & 2 & 11.76 \\
\hline Disordered Proliferative phase & 5 & 29.41 \\
\hline Total & 17 & 100 \\
\hline \multicolumn{3}{|l|}{ ORGANIC causes } \\
\hline Histopathological diagnosis & Number $(\mathbf{N})$ & Percentage $(\%)$ \\
\hline Simple Hyperplasia & 44 & 88 \\
\hline Complex Hyperplasia & 4 & 8 \\
\hline Atypical hyperplasia & 2 & 4 \\
\hline Polyp & 20 & 28.57 \\
\hline Total & 70 & 100 \\
\hline
\end{tabular}

Table 3: Histopathological spectrum of the lesions according to the age group

\begin{tabular}{|c|c|c|c|c|c|}
\hline \multirow[b]{2}{*}{$\begin{array}{l}\text { Histopathological } \\
\text { Diagnosis }\end{array}$} & \multicolumn{4}{|c|}{ Age of the patients } & \multirow[b]{2}{*}{ Total } \\
\hline & $\begin{array}{l}20-29 y e a r s \\
N(\%)\end{array}$ & $\begin{array}{l}\text { 30-39years } \\
\mathbf{N}(\%)\end{array}$ & $\begin{array}{l}\text { 40-49years } \\
\text { N }(\%)\end{array}$ & $\begin{array}{l}\text { 50-59years } \\
\mathbf{N}(\%)\end{array}$ & \\
\hline Proliferative endometrium & $4(4.5)$ & $3(3.4)$ & $2(2.2)$ & $1(1.1)$ & $10(11.49)$ \\
\hline Secretory endometrium & 0 & 0 & $2(2.2)$ & 0 & $2(2.2)$ \\
\hline Disordered Proliferative phase & $1(1.1)$ & $3(3.4)$ & $1(1.1)$ & 0 & $5(5.74)$ \\
\hline Hyperplasia & $1(1.1)$ & $16(18.3)$ & $21(24.1)$ & $12(13.7)$ & $50(57.47)$ \\
\hline Polyp & $4(4.5)$ & $7(8)$ & $9(10.3)$ & 0 & $20(22.98)$ \\
\hline Total & $10(11.49)$ & $29(33.33)$ & $35(40.22)$ & $13(14.94)$ & $87(100)$ \\
\hline
\end{tabular}

Table 4: Co - relation of sonological and histopathological findings

\begin{tabular}{|l|c|c|c|c|}
\hline \multirow{2}{*}{ Histopathological diagnosis } & Bulky uterus & $\begin{array}{c}\text { Thickened } \\
\text { Endometrium }\end{array}$ & $\begin{array}{c}\text { Polyp } \\
\text { Total cases } \\
\text { N }(\%)\end{array}$ \\
\cline { 2 - 5 } & & 4 & 0 & $10(11.49)$ \\
\hline Proliferative endometrium & 6 & 1 & 0 & $2(2.29)$ \\
\hline Secretory endometrium & 1 & 3 & 0 & $5(5.74)$ \\
\hline Disordered Proliferative phase & 2 & 36 & 0 & $50(57.47)$ \\
\hline Hyperplasia & 14 & 4 & 16 & $20(22.98)$ \\
\hline Polyp & 0 & 48 & 16 & $87(100)$ \\
\hline Total & 23 & & & 0 \\
\hline
\end{tabular}

Table 5: Co-relation of endometrial thickness (ET) with histopathological findings

\begin{tabular}{|l|c|c|c|c|c|c|}
\hline \multirow{2}{*}{$\begin{array}{l}\text { Endometrial } \\
\text { thickness }\end{array}$} & \multicolumn{5}{|c|}{ Histopathological diagnosis } & Total \\
\cline { 2 - 7 } & Hyperplasia & Polyp & $\begin{array}{c}\text { Proliferative } \\
\text { endometrium }\end{array}$ & $\begin{array}{c}\text { Secretory } \\
\text { endometrium }\end{array}$ & $\begin{array}{c}\text { Disordered } \\
\text { Proliferative phase }\end{array}$ & 0 \\
\hline$>15 \mathrm{~mm}$ & 25 & 1 & 0 & 0 & 0 & 26 \\
\hline $7-15 \mathrm{~mm}$ & 11 & 3 & 1 & 0 & 0 & 3 \\
\hline $4-7 \mathrm{~mm}$ & 0 & 0 & 3 & 1 & 3 & 48 \\
\hline Total & 36 & 4 & 4 & 0 & 3 & \\
\hline
\end{tabular}




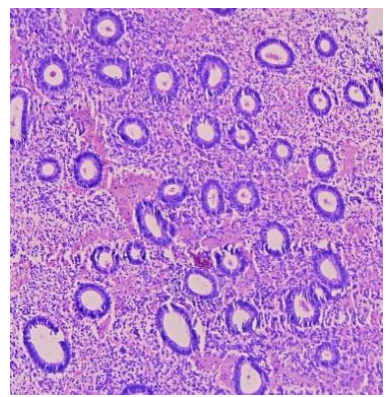

Fig. 1: Simple Hyperplasia- Increase in the number of glands which are round and regular $(\mathrm{H} \& \mathrm{E}, 10 \mathrm{X})$

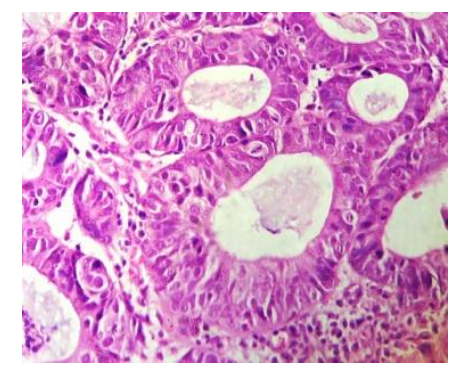

Fig. 2: Complex Atypical Hyperplasia-closely packed glands are cytologically atypical with marked stratification, enlarged and hyperchromatic nuclei, anisonuclesis and prominent nucleoli. (H \& E, 40X)

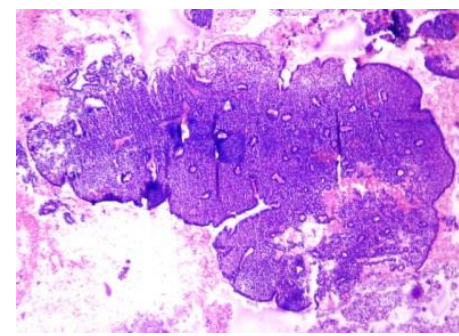

Fig. 3: Polyp - solid intact endometrial tissue fragment lined by surface epithelium (H\&E, 4X)

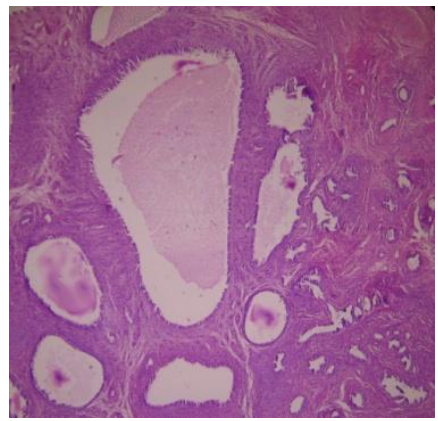

Fig. 4: Polyp- showing cystically dilated glands and fibrotic stroma $(\mathrm{H} \& \mathrm{E}, 10 \mathrm{X})$

\section{Discussion}

Abnormal uterine bleeding (AUB) is the most common complaint among women. It affects the health of the individual causing a substantial decrease in the individual's potential. There is a need to have thorough knowledge on the pathology of abnormal uterine bleeding so that unwanted complicated surgeries can be prevented.

In the present study patients of all age groups are included and sonographic - histopathological correlation was done whilst most other studies were done on the perimenopausal women and were either based on hysterectomy specimens or only histopathological evaluation (sonological findings were not taken into consideration).

AUB was found to be the indication for endometrial biopsy in majority of the cases $(91.42 \%)$ in our study. This percentage of cases shows that a higher number of endometrial biopsies are being done to evaluate cause of AUB. The maximum patients were in the age group of $40-49$ years $(40.22 \%)$. A similar high incidence was reported by Gopalan $\mathrm{U}$ et $\mathrm{al},{ }^{5} \mathrm{~S}$ Vaidya et al, ${ }^{11}$ Preeti Singh et al, ${ }^{12}$ Rupal Shah et al. ${ }^{13}$ The high incidence of AUB in this age group may be because of their climacteric period, ${ }^{9}$ prior to the which changes occur in the ovarian-pituitary function. ${ }^{15}$

AUB presents with different bleeding patterns. In the present study menorrhagia is the most common complaint $(59.7 \%)$ which is comparable with Dr. Somnath et al ${ }^{9}(58.7 \%)$ study which included only the pre and postmenopausal age group. In the studies done by Preeti Singh et al,,$^{12}$ Anam Khan et al ${ }^{14}$ also showed menorrhagia as the chief complaint. A high incidence of multiparous $(79.3 \%)$ patients was seen in the present study, which is similar to the studies conducted on perimenopausal women by Dr.G.L.Shobhitha et al, ${ }^{16} \mathrm{Dr}$ Lakshmi Nair, ${ }^{17}$ Archana Bhosle ${ }^{18}$ with majority of the patients being multiparous.

As per FIGO the causes of AUB have been broadly classified into structural/organic causes and non-structural/functional causes.

Histopathological examination of the endometrium revealed a variety of patterns. In our study, Proliferative endometrium (11.49\%) was found to be predominant functional cause. The study done by Pooja et $\mathrm{al}^{7}$ also had proliferative endometrium (25\%) as the most common functional cause. Of the 70 cases with organic pathology, endometrial hyperplasia's $(71.42 \%)$ were most common, correlating with S Vaidya et al ${ }^{11}$ where $61.11 \%$ cases had hyperplasia. Among the total 72 cases of organic pathology, simple hyperplasia is the most common hyperplasia with an incidence of $88 \%$, correlating with S Vaidya et al ${ }^{11}$ where $97.44 \%$ of cases had simple hyperplasia.

In the present study, Hyperplasia was found to be the most common lesion in perimenopausal (40-49yr) age group with an incidence of $24 \%$. The study done by Sajitha et $\mathrm{al}^{8}(14.1 \%)$ and Dr.G.L.Shobitha et $\mathrm{al}^{17}$ $(45.5 \%)$ showed a higher incidence in the same age group. Endometrial hyperplasias are characterized by increased proliferation of endometrial glands (stroma may also show proliferation) when compared with the normal endometrium. The current WHO classification 
of endometrial hyperplasias is based on architectural and cytological features. Based on architecture, hyperplasias are classified as simple and complex and on the basis of cytological (nuclear) features into hyperplasias with-atypia and without-atypia. ${ }^{19}$ Simple hyperplasia is characterized by increase in gland- tostromal ratio due to increased proliferation of glands relative to stroma. ${ }^{1}$ The glands are round, regular or cystic and angular. The lining epithelium is pseudostratified with cells showing uniform, oval nuclei. ${ }^{20}$ Disordered Proliferative phase is a not a welldefined category in which the endometrium has the appearance of hyperplasia but does not fulfill the criteria of simple hyperplasia. ${ }^{19,21}$ It is a focal process with no increase in endometrial volume and the appearance of endometrium cannot be dated to any specific time of menstrual cycle. ${ }^{21}$ In Complex hyperplasia the glands show marked crowding with back-to-back arrangement and scant stroma. The glands may show branching, irregular angularity and side buds. ${ }^{11} 19$ Atypical hyperplasia's are characterized by abnormal cytological features comprising of loss of polarity, anisonucleosis, nuclear enlargement with prominent nucleoli and hyperchromatism. ${ }^{19}$ Simple hyperplasia with atypia are unusual. ${ }^{1}$

It is difficult to distinguish between complex atypical hyperplasia and well -differentiated carcinoma on endometrial biopsies where invasion cannot be assessed. However microscopic features helpful for diagnosing a carcinoma include the complex architectural pattern of the disorderly arranged glands, papillae formation and solid or cribriform appearance. 22 Also in hyperplasia the stroma is retained between the glands when compared to carcinoma. ${ }^{19}$

An alternate classification system has been proposed as the WHO classification was questioned for its complexity and poor reproducibility index. This classification includes two broad categories. The first category includes endometrial hyperplasia's of benign nature and with a minimal risk for development into malignancy. The second category includes endometrial intraepithelial neoplasia (EIN) is a premalignant condition with higher chances of progression to malignancy. ${ }^{22}$ The diagnostic criteria for EIN are the presence of cytologic atypia in an architecturally crowded area which should be atleast $1 \mathrm{~mm}$ in diameter and the percentage of stromal volume should be less than $55 \%$. Also the benign lesions such as metaplasia's mimicking EIN must be excluded along with carcinoma. ${ }^{19}$

The next common pathology followed by hyperplasias was found to be polyps $22.98 \%$. Polyps are exophytic masses that protrude into the endometrial cavity. Histologically polys are diagnosed by the presence of solid intact endometrial tissue fragment lined by surface epithelium on three sides. The glands are cystically dilated with presence of fibrotic stroma and thick-walled blood vessels. ${ }^{19}$ In a study done by
Abid et al, ${ }^{23}$ polyps were found in $14 \%$ cases. About $3.7 \%$ to $65 \%$ cases of AUB is due to polyps and also the incidence of polyps increases with age. ${ }^{3}$ In the present study the incidence of polyps was found to increase with each decade and was found to have a maximum incidence in the perimenopausal age group $(10.3 \%)$. The study done by Doraiswami et al also showed a high incidence of polyps $(11.2 \%)$ in the perimenopausal age group. ${ }^{24}$ Endometrial hyperplasias appear to be most common cause of abnormal bleeding patterns in the perimenopausal age group as they are in the climacteric period where anovulatory cycles occur causing persistent high levels of estrogen which leads to the development of hyperplasia and polyps. ${ }^{13}$ In the present study $19.4 \%$ cases of hyperplasias were in the reproductive age group $(20-39 \mathrm{yr})$.This signifies the fact that irrespective of the age group it is necessary to evaluate a case of AUB as hyperplasias are considered to be precursors of endometrial malignancy with a considerable risk of $5-10 \%{ }^{8}$ There were no cases of polyp noted above 50yr. The absence of cases could be due to their earlier detection and management.

Though endometrial biopsy and histopathological examination provides with a specific diagnosis, it has a false negative rate of $2 \%$ to $6 \%$. D\&C being a blind procedure may lead to diagnostic error ${ }^{13}$ due to the inadequacy of sampling as $18 \%$ of focal lesions such as polyps or any focal changes in the endometrium may be missed which usually occurs in direct sampling methods. ${ }^{9}$

Transvaginal sonography is a good method to study the endometrial abnormalities with high sensitivity (upto $92 \%$ ). ${ }^{9}$ It is an effective outpatient procedure with good patient compliance which helps to identify suitable candidates for endometrial biopsy based on the presence/absence of anatomic endometrial pathology and thickened endometrium (in global thickening blind sampling can be done whereas focally thickened endometrium needs direct sampling). ${ }^{25}$

Sonological findings correlated with histopathology for organic causes in 70cases out of the total 87 cases and this correlation was statistically significant with $\mathrm{p}$ value $=0.000$ and the sensitivity of sonography for detecting an organic pathology is $80.4 \%$. All the cases with an endometrial thickness (ET) $>15 \mathrm{~mm}$ had hyperplasia. Cases with $4-7 \mathrm{~mm}$ endometrial thickness had no organic pathology. So the cut-off value for the endometrial thickness below which no pathology was observed is $7 \mathrm{~mm}$. This correlation was statistically proven to be highly significant with $p$ value $=0.000$. In a study done on perimenopausal age group by Shobhitha et $\mathrm{al}^{16}$ the cut of value of ET was $8 \mathrm{~mm}$ to detect the presence of pathology. This study has also made a mention of other studies which had differing cut -off values of endometrial thickness. ${ }^{16}$

The histopathological findings in the present study show discordance with the other studies (Table 6), as in other studies a predominance of functional pathology 
was found. It may be due to the fact that in our study only the patients presenting with abnormal USG findings and their respective endometrial biopsies were included, whereas the other studies analyzed only the histopathological findings of cases with AUB. These comparisons highlight to the fact that with the combination of sonology and histopathology there is a higher likelihood of identifying the organic causes of AUB and thus appropriately triage the patients for the management.

Table 6: Comparison with other studies

\begin{tabular}{|c|c|c|c|c|c|}
\hline S.No & $\begin{array}{c}\text { Histopathological } \\
\text { diagnosis }\end{array}$ & $\begin{array}{c}\text { S Vaidya } \\
\text { et al }{ }^{11}(\%)\end{array}$ & $\begin{array}{c}\text { Pooja agarwal } \\
\text { et } \mathrm{al}^{7}(\%)\end{array}$ & $\begin{array}{c}\text { Sajitha et } a l^{8} \\
(\%)\end{array}$ & $\begin{array}{c}\text { Present } \\
\text { Study }(\%)\end{array}$ \\
\hline 1. & $\begin{array}{l}\text { Proliferative } \\
\text { endometrium }\end{array}$ & 18.36 & 25 & 12.2 & 11.49 \\
\hline 2 & $\begin{array}{c}\text { Secretory } \\
\text { endometrium }\end{array}$ & 22.58 & 15.80 & 16.7 & 2.29 \\
\hline 3 & Mixed pattern & $\begin{array}{ll}----- \\
\end{array}$ & ----------- & 3.84 & --------- \\
\hline 4 & $\begin{array}{c}\text { Atrophic } \\
\text { endometrium }\end{array}$ & 4.71 & 21.90 & 5.12 & --------- \\
\hline 5 & Basal endometrium & ---------- & 7.30 & --------- & -------- \\
\hline 6 & $\begin{array}{c}\text { Menstrual } \\
\text { endometrium }\end{array}$ & ---------- & ------------ & 1.28 & --------- \\
\hline 7 & Weakly proliferative & 9.68 & -------------- & & -------- \\
\hline 8 & $\begin{array}{c}\text { Disordered } \\
\text { Proliferative phase }\end{array}$ & 13.40 & 6 & 12.2 & 5.74 \\
\hline 9 & $\begin{array}{c}\text { Deficient luteal } \\
\text { Phase }\end{array}$ & 1.24 & ---------------- & 2.6 & --------- \\
\hline 10 & $\begin{array}{c}\text { Endometrial } \\
\text { Polyps }\end{array}$ & 1.24 & 7.30 & 5.12 & 22.98 \\
\hline 11 & Endometritis & 3.23 & 2.40 & 0.64 & ---------- \\
\hline 12 & $\begin{array}{l}\text { Endometrial } \\
\text { Hyperplasia }\end{array}$ & 10.92 & 9.60 & 25 & 57.47 \\
\hline 13 & Pill endometrium & 6.20 & ----------- & 7.7 & --------- \\
\hline 14 & $\begin{array}{l}\text { Endometrial } \\
\text { Carcinoma }\end{array}$ & 2.48 & 2.40 & 4.5 & --------- \\
\hline 15 & $\begin{array}{c}\text { Endometrial stromal } \\
\text { nodule }\end{array}$ & -------- & 1.20 & ------------ & ----------- \\
\hline 16 & $\begin{array}{c}\text { Endometrial stromal } \\
\text { sarcoma }\end{array}$ & --------- & --------- & 0.64 & ------------- \\
\hline 17 & Other carcinomas & -------- & ---------- & 1.28 & ------------- \\
\hline 18 & $\begin{array}{l}\text { Unsatisfactory for } \\
\text { evaluation }\end{array}$ & 5.96 & ------------- & 1.28 & Excluded \\
\hline 19 & Total & 100 & 100 & 100 & 100 \\
\hline
\end{tabular}

\section{Conclusion}

AUB is one of the most common gynecological complaint affecting all the age groups which requires a pathology based treatment. Hence there is a need to identify the exact cause of AUB. A strategic approach with thorough clinical history, patient examination and tests helps to narrow the wide range of differential diagnosis. Each and every diagnostic test has its own merits and demerits hence there is a need to establish a panel of investigations which do not cause financial burden to the patients and by which a preliminary diagnosis is reached. Sonological examination can be used as screening procedure to select the patients with organic pathology for endometrial biopsy. A combination of sonography with histopathology provides an accurate diagnosis for AUB in most of the cases, specifically those with organic pathology.

\section{References}

1. Ellenson LH, Pirog EC. The female genital tract. In: Kumar V, Abbas AK, Fausto N, Aster AC, editors. Robbins and Cotran pathologic basis of disease. 8th ed. Philadelphia (PA): Saunders Elsevier; c2010. p. 1005-63.

2. Khan S, Hameed S, Umber A. Histopathological pattern of endometrium on diagnostic $\mathrm{D} \& \mathrm{C}$ in patient with abnormal uterine bleeding. Annals 2011;17(2):166-70. 
3. Whitaker L, Critchley H.O. Abnormal uterine bleeding. Best Practice \& Research Clinical Obstetrics and Gynaecology 2016;34:54-65.

4. Mencoglia L, Perino A, Hamou J. Hysteroscopy in perimenopausal and post-menopausal women with abnormal uterine bleeding. J Reprod Med 1987;32:57782.

5. Gopalan U, Rajendiran S, Karnaboopathy R. Study of endometrial histopathology in women with abnormal uterine bleeding. Int J Reprod Contracept Obstet Gynecol 2017;6(3):824-28.

6. Kumar P, Malhotra N. Clinical types of abnormal uterine bleeding. In: Kumar P, editor. Jeffcoate's Principle of Gynecology. 7th ed. New Delhi: Jaypee Brothers Medical Publishers (P) Ltd; 2008. p. 599.

7. Agarwal P, Garg R, Rai N, Prakash P. Abnormal uterine bleeding. J South Asian Feder Menopause Soc 2016;4(1):22-26.

8. Sajitha K, Padma SK, Shetty KJ, KishanPrasad HL, Permi HS, Hegde P. Study of histopathological pattern of endometrium in abnormal uterine bleeding. CHRISMED J Health Res 2014;1:76-81.

9. Ghosh S, Chowdhury AR, Chakraborty S. Abnormal uterine bleeding: histopathology with clinical correlates in premenopausal vis-a-vis postmenopausal women, with special reference to preoperative diagnostic imaging. British Journal Of Pharmaceutical And Medical Research 2017;2(1):327-41.

10. Hunter DC, McClure N. Abnormal uterine bleeding: an evaluation endometrial biopsy, vaginal ultrasound and outpatient hysteroscopy. The Ulster Medical Journal 2001;70(1):25-30.

11. Vaidya S, Lakhey M, Vaidya S, Sharma PK, Hirachand S, Lama S et al. Histopathological pattern of abnormal uterine bleeding in endometrial biopsies. Nepal Med Coll J 2013;15(1):74-7.

12. Singh P, Jaiswal VK, Garg P. Endometrial patterns in abnormal uterine bleeding. Int J Biomed Res 2016;7(5):244-50.

13. Shah RJ, Dayal A, Kothari SL, Patel SM, Dalal B. Histopathological interpretation of endometrium in abnormal uterine bleeding. Int J Med Sci Public Health 2014;3(4):452-56

14. Khan A, Khandelwal R, Arya S, Pant H. Study of endometrial pathology in abnormal uterine bleeding. Internal Journal of Biomedical and Advance Research 2017;8(2):38-43.

15. Davey DA. Dysfunctional uterine bleeding. In: Whitfield CR, editor. Dewhurst's textbook of obstetrics and gynaecology for postgraduates. Glasgow: Blackwell Science; 1997. p. 590-608.

16. Shobhitha GL, Kumari VI, Priya PL, Sundari. Endometrial study by TVS and it's correlation with histopathology in abnormal uterine bleeding. IOSR Journal of Dental and Medical Sciences 2015;14(4):2132.

17. Nair L, Christopher U. A retrospective analysis of causes, diagnosis, and management of AUB in perimenopausal women. Indian j. med res. pharm. sci 2015;2(7):52-54.

18. Bhosle A, Fonseca M. Evaluation and histopathological correlation of abnormal uterine bleeding in perimenopausal women. Bombay Hospital Journal 2010;52(1):69-72.

19. Hagemann I.S, Pfeifer JD, Huettner PC. The uterine corpus. In: Wick MR, Livolsi VA, Pfeifer JD, Stelow EB, Wakely PE Jr, editors._Silverberg's principles and practice of surgical pathology and cytopathology. 5th ed. Vol 4.
Cambridge:Cambridge University Press; 2015. p. 2657723.

20. Tavassoli FA, Devilee P. World Health Organization of tumours: pathology and genetics of tumors of the breast and female genital organs. IARC Press: Lyon; 2003. p. 218-32.

21. Devi J, Aziz N. Study of "Histopathological pattern of endometrium in abnormal uterine bleeding in the age group 40-60 years" -A study of 500 cases. Int. j.med. sci. clin. Invent 2014;1(10):579-85.

22. Rosai J, Ackerman LV. Rosai and Ackerman'surgical pathology. 10th ed. Vol 2. Edinburgh (NY) : Mosby; 2011. p. 1477-540.

23. Abid M, Hashmi AA, Malik B, Haroon S, Faridi N, Edhi $\mathrm{MM}$ et al. Clinical pattern and spectrum of endometrial pathologies in patients with abnormal uterine bleeding in Pakistan: need to adopt a more conservative approach to treatment. BMC Womens Health 2014 Nov 5;14:132.

24. Doraiswami S, Johnson T, Rao S, Rajkumar A, Vijayaraghavan J, Panicker V. Study of endometrial pathology in abnormal uterine bleeding. J. Obstet. Gynaecol India. 2011;61:426-430.

25. Goldstein SR. The role of transvaginal ultrasound or endometrial biopsy in the evaluation of the menopausal endometrium. Am J Obstet Gynecol 2009;201:5-11. 